\title{
L-theanine inhibits nicotine-induced dependence via regulation of the nicotine acetylcholine receptor-dopamine reward pathway
}

\author{
DI XiaoJing ${ }^{1 \dagger}$, YAN JingQi $^{1 \dagger}$, ZHAO Yan ${ }^{2}$, CHANG YanZhong ${ }^{3} \&$ ZHAO BaoLu ${ }^{1^{*}}$ \\ ${ }^{1}$ State Key Laboratory of Brain and Cognitive Science, Institute of Biophysics, Chinese Academy of Sciences, Beijing 100101, China; \\ ${ }^{2}$ Department of Food Sciences and Technology, Harbin Institute of Technology at Weihai, Weihai 264209, China; \\ ${ }^{3}$ Institute of Molecular Neurobiology, Hebei Normal University, Shijiazhuang 050016, China
}

Received August 7, 2012; accepted October 15, 2012

\begin{abstract}
In this study, the inhibitory effect of L-theanine, an amino acid derivative of tea, on the rewarding effects of nicotine and its underlying mechanisms of action were studied. We found that L-theanine inhibited the rewarding effects of nicotine in a conditioned place preference (CPP) model of the mouse and reduced the excitatory status induced by nicotine in SH-SY5Y cells to the same extent as the nicotine receptor inhibitor dihydro-beta-erythroidine (DH $\beta E$ ). Further studies using high performance liquid chromatography, western blotting and immunofluorescence staining analyses showed that L-theanine significantly inhibited nicotine-induced tyrosine hydroxylase $(\mathrm{TH})$ expression and dopamine production in the midbrain of mice. L-theanine treatment also reduced the upregulation of the $\alpha_{4}, \beta_{2}$ and $\alpha_{7}$ nicotine acetylcholine receptor (nAChR) subunits induced by nicotine in mouse brain regions that related to the dopamine reward pathway, thus decreasing the number of cells that could react to nicotine. In addition, L-theanine treatment inhibited nicotine-induced c-Fos expression in the reward circuit related areas of the mouse brain. Knockdown of c-Fos by siRNA inhibited the excitatory status of cells but not the upregulation of TH induced by nicotine in SH-SY5Y cells. Overall, the present study showed that L-theanine reduced the nicotine-induced reward effects via inhibition of the nAChR-dopamine reward pathway. These results may offer new therapeutic strategies for treatment of tobacco addiction.
\end{abstract}

nicotine addiction, L-theanine, nicotine acetylcholine receptor (nAChR), dopamine, conditioned place preference (CPP)

Citation: Di X J, Yan J Q, Zhao Y, et al. L-theanine inhibits nicotine-induced dependence via regulation of the nicotine acetylcholine receptor-dopamine reward pathway. Sci China Life Sci, 2012, 55: 1064-1074, doi: 10.1007/s11427-012-4401-0

Cigarette smoking has been linked to many life threatening diseases including heart disease, cancer and chronic obstructive pulmonary disease [1-3]. It is estimated that there are approximately 1.25 billion smokers in the world, with 5 million dying every year because of smoking-related diseases. Thus, cigarette smoking has become one of the largest international public health problems. Although many methods/campaigns have been developed for smoking cessation [4-6], quitting smoking is extremely difficult because

\footnotetext{
$\dagger$ Contributed equally to this work

*Corresponding author (email: zhaobl@ sun5.ibp.ac.cn)
}

of the addictive nature of nicotine.

Nicotine addiction is a chronic recurrent disease that is caused by repetitive uptake of nicotine [7]. Similar to other addictive drugs, nicotine addiction has an intimate connection with the mesostriatal dopamine reward circuit, in which the activity of dopamine neurons can be reinforced by addictive drugs including nicotine. The mesostriatal dopamine reward circuit, mainly composed of the ventral tegmental area (VTA), prefrontal cortex (PFC) and nucleus accumbens (NAc), expresses high levels of nicotine acetylcholine receptors (nAchRs). These receptors are thought to mediate several main behavioral effects of nicotine, including the 
regulation of conditioned place preference (CPP) formation $[8,9]$. Mounting data has indicated that the number of $\mathrm{nA}-$ chRs increases after chronic nicotine uptake in both animal models and human subjects. In vitro experiments have shown that the expression of $\alpha_{4} \beta_{2} n$ AchRs increases significantly after prolonged nicotine treatment $[10,11]$. Moreover, the upregulation of $\alpha_{4} \beta_{2}$ nAchRs expression has also been found in the brains of smokers [12]. It is proposed that the $\alpha_{4} \beta_{2}$ nAchRs, $\alpha_{7}$ nAchR and the transcription factor c-Fos are necessary for the formation of the stable neural adaptation during the exposure of nicotine $[13,14]$. These findings suggest that inhibition of the expression or the function of these subtypes of nAchRs in the mesostriatal reward circuit system may promote the cessation of nicotine addiction.

L-theanine is an amino acid derivative primarily found in tea. It has been reported to promote relaxation and have neuroprotective effects. It is also shown to have an antagonistic effect on the excitement induced by caffeine [15]. Recently, we have studied the effect of a newly developed tea filter and its components on smoking addiction and found an unprecedented smoke cessation effect of cigarette filters. Moreover, we identified that L-theanine had an inhibitory effect on nicotine addiction [16]. In this study, we further investigated whether L-theanine regulates the behavioral and biochemical processes underlying the nicotine-induced reward effects. With this aim, we used the mouse CPP model and human neuroblastoma SH-SY5Y cells to assess the inhibitory effect of L-theanine on the rewarding effects induced by nicotine and its underlying mechanisms of action.

\section{Methods}

\subsection{Reagents}

Dulbecco's modified Eagle's medium (DMEM), fetal calf serum, and HEPES were purchased from GIBCO BRL (Grand Island, NY); ethylenediaminotetraacetic acid (EDTA), trypsin, penicillin, DH $\beta E$ and streptomycin were purchased from Sigma Chemical Co. (St. Louis, MO, USA); antibodies against $\mathrm{AChR}_{4}$ (sc-74519), AChR $\beta_{2}$ (sc11372), $\mathrm{AChR} \alpha_{7}$ (sc-11372), TH (sc-25269), c-FOS (sc-52) and $\beta$-Actin (sc-1616-R) were purchased from Santa Cruz Biotechnology (Santa Cruz, CA, USA); 2-NBDG was purchased from Invitrogen Corporation (Invitrogen, Carlsbad, CA, USA); Vectastain ABC kit and DAB kit were purchased from Vector Corporation (Burlingame, USA). L-theanine, with a purity of $98.11 \%$ (analyzed by high performance liquid chromatography (HPLC)), was a generous gift from Hangzhou Gosun Biotechnologies Co., Ltd. (Hangzhou, China); nicotine, with a purity of 99\%, was a generous gift from the tobacco Institute of Zhengzhou (Zhengzhou, China). All other chemicals were made in China and were of analytical grade.

\subsection{Animal treatment}

Animal experiments were carried out in accordance with the NIH Guide for the Care and Use of Laboratory Animals and were approved by the local animal care committee. Six- to eight-week-old female C57BL/6J mice were purchased from the Institute of Laboratory Animal Science, Chinese Academy of Medical Science and housed in an SPF (specific parasite free) environment at $22^{\circ} \mathrm{C}$ with a 12 -h light-dark cycle. Food (Mouse Diet, Beijing Experiment Animal Center) and water were available ad libitum. Chemicals were dissolved in $0.9 \%(\mathrm{w} / \mathrm{v})$ physiological saline and injected subcutaneously. Animals were randomly divided into the following groups $(n=10)$ for treatment with different chemicals: control mice were injected with $0.9 \%$ (w/v) physiological saline subcutaneously (s.c.); nicotine mice were injected with nicotine $\left(0.5 \mathrm{mg} \mathrm{kg}^{-1} \mathrm{~d}^{-1}\right.$, s.c. $)$; Th- $\mathrm{L}$ mice were injected with L-theanine $\left(250 \mathrm{mg} \mathrm{kg}^{-1} \mathrm{~d}^{-1}\right.$, s.c.); Th-H mice were injected with L-theanine $(500 \mathrm{mg}$ $\mathrm{kg}^{-1} \mathrm{~d}^{-1}$, s.c.); Th-L(N) mice were injected with L-theanine (250 $\mathrm{mg} \mathrm{kg}^{-1} \mathrm{~d}^{-1}$, s.c.) and nicotine $\left(0.5 \mathrm{mg} \mathrm{kg}^{-1} \mathrm{~d}^{-1}\right.$, s.c.); $\mathrm{Th}-\mathrm{H}(\mathrm{N})$ mice were injected with L-theanine $\left(500 \mathrm{mg} \mathrm{kg}^{-1}\right.$ $\mathrm{d}^{-1}$, s.c.) and nicotine (0.5 $\mathrm{mg} \mathrm{kg}^{-1} \mathrm{~d}^{-1}$, s.c.); $\mathrm{DH} \beta \mathrm{E}(\mathrm{N})$ mice were injected with $\mathrm{DH} \beta \mathrm{E}\left(2.0 \mathrm{mg} \mathrm{kg}^{-1} \mathrm{~d}^{-1}\right.$, s.c. $)$ and nicotine $\left(0.5 \mathrm{mg} \mathrm{kg}^{-1} \mathrm{~d}^{-1}\right.$, s.c.) [17]. Mice were injected daily with nicotine or physiological saline. L-theanine and $\mathrm{DH} \beta \mathrm{E}$ were administered 15 min before nicotine injection.

\subsection{Conditioned place preference (CPP) test}

CPP is a behavioral test that is usually used to study the rewarding properties of nicotine and other drugs. This procedure consists of three phases: preconditioning, conditioning, and post conditioning [18,19]. In our procedure, days 1 and 2 were the preconditioning days and mice were allowed to roam freely for $900 \mathrm{~s}$ in a rectangular box, which was separated by a narrow compartment. The time that an individual mouse spent in each compartment was recorded. Mice were then divided into groups with an unconditioned preference ( $n=10$ mice per group) according to these data. On days 3-9, the mice were injected s.c. with saline or chemicals as described earlier and immediately placed in one of the pairing compartments for $30 \mathrm{~min}$. Five hours later, the mice were injected with a combination of chemicals or saline and immediately placed in the opposite chamber for $30 \mathrm{~min}$. Control groups received saline on both sides of the chamber. On day 10, the animals were once again allowed to roam freely among the three compartments for $900 \mathrm{~s}$ and the time spent in each compartment was recorded. The animals were drug-free on preconditioning and post conditioning days.

\subsection{Cell culture and glucose-uptake using the 2-NBDG assay}

Human neuroblastoma SH-SY5Y cells were maintained in a 
medium consisting of DMEM supplemented with fetal bovine serum $(10 \%, \mathrm{v} / \mathrm{v})$, penicillin $\left(100 \mathrm{IU} \mathrm{mL}^{-1}\right)$, and streptomycin $\left(100 \mu \mathrm{g} \mathrm{mL}^{-1}\right)$ in a humidified $5 \% \mathrm{CO}_{2} / 95 \%$ air incubator at $37^{\circ} \mathrm{C}$. Cells pretreated with $\mathrm{DH} \beta \mathrm{E}\left(50 \mu \mathrm{mol} \mathrm{L}{ }^{-1}\right)$ or L-theanine $\left(100 \mu \mathrm{mol} \mathrm{L}{ }^{-1}\right)$ for $30 \mathrm{~min}$ were treated with or without nicotine $\left(10 \mu \mathrm{mol} \mathrm{L}{ }^{-1}\right)$ for $24 \mathrm{~h}$. The cells were then washed with KRB buffer (Krebs-Ringer Bicarbonate Buffer) three times, incubated with 2-NBDG (2-[N-(7nitrobenz-2-oxa-1,3-diazol-4-yl)amino]; Invitrogen, CA, USA) for $20 \mathrm{~min}$, and washed with KRB buffer three times. The fluorescence was examined under a fluorescence microscope (Olympus, kx14e).

\subsection{Dopamine metabolism measured by HPLC with electrochemical detection}

Thirty minutes after subcutaneous injection of saline or different chemicals, mice were killed by cervical vertebra dislocation and both sides of the striatum were carefully isolated. Samples were weighed and homogenized in $1 \mathrm{~mL}$ of $0.2 \mathrm{~mol} \mathrm{~L}^{-1}$ perchloric acid. Tissue homogenates were then centrifuged at $20000 \times \mathrm{g}$ for $15 \mathrm{~min}$ at $4^{\circ} \mathrm{C}$ and the supernatants were collected for further analyses. The levels of striatal dopamine (DA) and its metabolites, 3,4-dihydroxyphenylacetic acid (DOPAC) and homovanillic acid (HVA) were determined by HPLC ESA-5600A Coularray system (ESA, USA) using a previously described method [20,21].

\subsection{Tyrosine hydroxylase (TH) immunohistochemistry}

Coronal mesencephalic sections $(14 \mu \mathrm{m})$ were processed for TH immunohistochemistry [22,23]. TH-positive neurons were immunolabeled by incubating the tissue sections successively with a mouse monoclonal anti-TH antibody $(1: 200)$ and biotinylated rabbit anti-mouse $\operatorname{IgG}(1: 100$; Vector Laboratories) following the staining procedure outlined by the manufactures of the Vectastain ABC kit (Vector Laboratories) in combination with $\mathrm{DAB}$ reagents. The total positive TH deposits in the substantia nigra pars compacta were examined under bright field using a Leica DM2500 microscope and images were obtained with a DFC 300 FX camera.

\subsection{Western blotting assay}

The tissues of the ventral tegmental nucleus (VTA), nucleus accumbens (NAc) and prefrontal cortex (PFC) were homogenized on ice in buffer $\left(50 \mathrm{mmol} \mathrm{L}^{-1}\right.$ Tris-Cl, $150 \mathrm{mmol}$ $\mathrm{L}^{-1} \mathrm{NaCl}, 0.02 \mathrm{mmol} \mathrm{L}^{-1} \mathrm{NaN}_{2}, 100 \mu \mathrm{g} \mathrm{mL}{ }^{-1} \mathrm{PMSF}, 1 \mu \mathrm{g}$ $\mathrm{mL}^{-1}$ Aprotinin and $1 \%(\mathrm{v} / \mathrm{v})$ Triton $\left.\mathrm{X}-100\right)$ for $30 \mathrm{~min}$. Tissue homogenates and cell lysates were then centrifuged at $12000 \times g$ for $25 \mathrm{~min}$ at $4^{\circ} \mathrm{C}$. Supernatants were collected and analyzed by Western blotting using the standard protocol. Band intensities were quantified using image analyzing software (NIH Image).

\subsection{Immunofluorescence staining}

SH-SY5Y cells were fixed in methanol/acetone $(1: 1)$. The fixed cells were then permeabilized in $1 \%(\mathrm{v} / \mathrm{v})$ Triton $\mathrm{X}-100$, and blocked with $1 \%(\mathrm{v} / \mathrm{v})$ normal goat serum for 30 min. Immunostaining was done by incubating the samples successively with antibodies specifically recognizing $\mathrm{TH}$ (sc-25269), c-FOS (sc-52) and fluorescein-conjugated goat anti-mouse IgG. The fluorescence was examined under a confocal laser scanning microscope (LSCMFV500).

\section{9 siRNA transfection}

siRNAs were designed and synthesized by GenePharma. The sequences against c-Fos were 5'-GGUGGAACAGUUAUCUCCATT-3' (sense) and 5'-UGGAGAUAACUGUUCCACCTT-3' (antisense). An antisense siRNA provided by the manufacturer that does not target rat, mouse, or human genes was used as a negative control $(\mathrm{Nc})$; the sequences were 5'-UUCUCCGAACGUGUCACGUTT-3' (sense) and 5'-ACGUGACACGUUCGGAGAATT-3' (antisense). In brief, $1 \times 10^{5} \mathrm{SH}-\mathrm{SY} 5 \mathrm{Y}$ cells $/ 35 \mathrm{~mm}$ dish were plated and cultured under normal conditions as described earlier until the cells reached about $80 \%$ confluency. The siRNAs were then transfected using Lipofectamine 2000 (Invitrogen Inc., USA) following the manufacturer's instructions.

\subsection{Statistical analysis}

One-way analysis of variance (ANOVA) was used to estimate the overall significance followed by post hoc Tukey's tests corrected for multiple comparisons [24]. Data are presented as the mean \pm SEM. A probability level of $5 \%$ $(P<0.05)$ was considered statistically significant.

\section{Results}

\subsection{L-theanine reduces the rewarding effects of nico- tine}

The effect of L-theanine on nicotine-induced rewarding was studied using the CPP test in a mouse model. Mice were treated with nicotine $\left(0.5 \mathrm{mg} \mathrm{kg}^{-1} \mathrm{~d}^{-1}\right.$, s.c.) for $14 \mathrm{~d}$ to induce the rewarding effects. As shown in Figure 1A, the time that the mice spent in the drug-paired compartment increased significantly after the treatment when compared with the control group. The preference for the drug-paired compartment induced by nicotine treatment was significantly inhibited when mice were pre-treated with L- theanine ( 250 or $500 \mathrm{mg} \mathrm{kg}^{-1} \mathrm{~d}^{-1}$; s.c.) or the inhibitor of nicotine receptor $(\mathrm{DH} \beta \mathrm{E})$ before nicotine treatment (Figure 1B), 

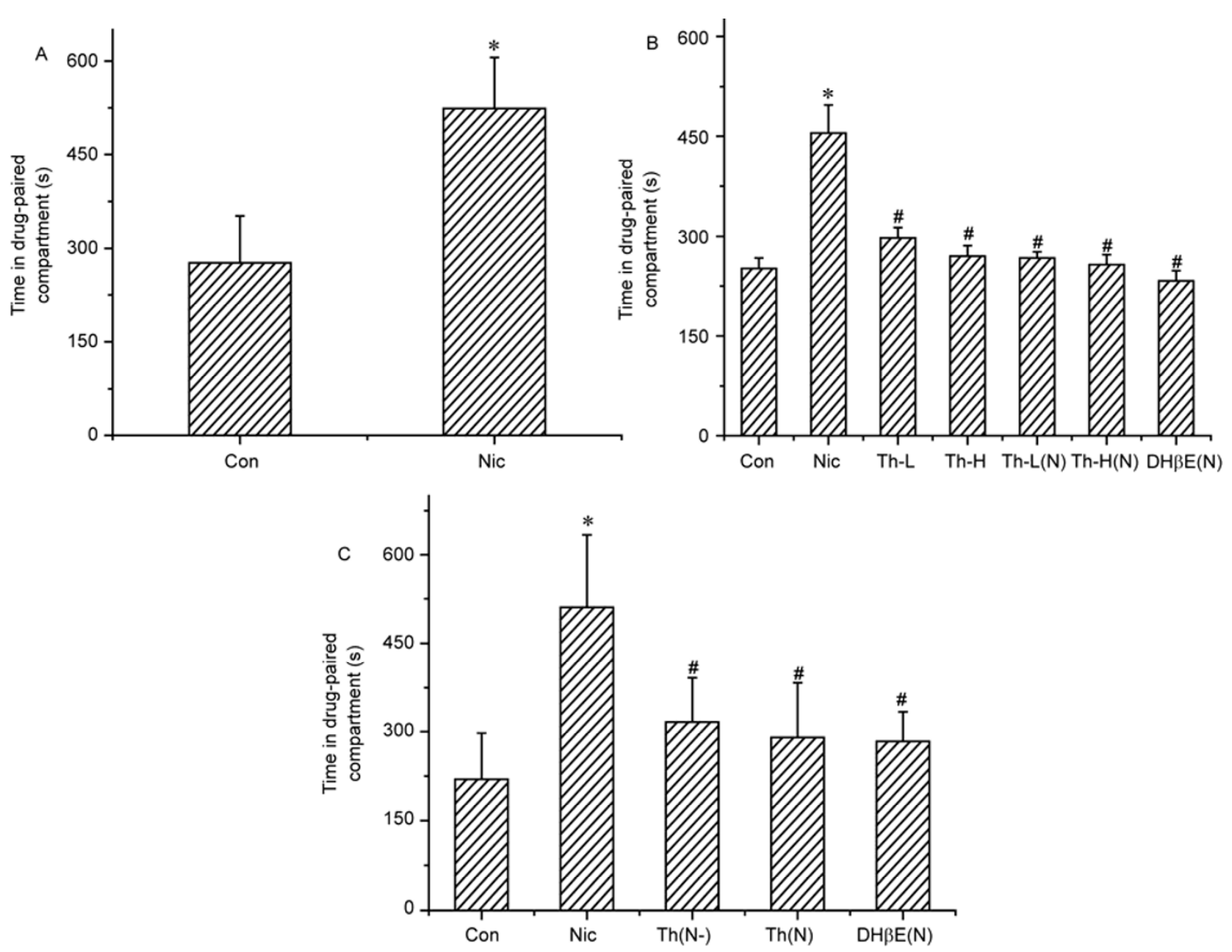

Figure 1 Effects of L-theanine on the rewarding effects induced by nicotine evaluated by the conditioned place preference (CPP) test. A, The rewarding effects induced by nicotine. Mice were injected with nicotine $\left(0.5 \mathrm{mg} \mathrm{kg}^{-1} \mathrm{~d}^{-1}\right)$ or physiological saline every day for $14 \mathrm{~d}$. The nicotine-induced rewarding effects were examined on day 17 using the CPP test. B, Effects of pretreatment of L-theanine on the rewarding effects induced by nicotine. Mice treated with nicotine were injected with different concentrations of L-theanine or DH $\beta E$ in physiological saline every day for $14 \mathrm{~d}$. L-theanine or DH $\beta E$ was administered $15 \mathrm{~min}$ before nicotine injection. The nicotine-induced rewarding effects on the mice were examined on day 17 using the CPP test. C, Effects of L-theanine on the rewarding effects already induced by nicotine. Mice were injected with nicotine or physiological saline every day for $14 \mathrm{~d}$. The nicotine-induced rewarding effects on mice were examined on day 17 using the CPP test. Starting from day 18, mice were administered with L-theanine $\left(500 \mathrm{mg} \mathrm{kg}^{-1} \mathrm{~d}^{-1}\right)$ alone, or with L-theanine or DH $\beta E 15$ min before nicotine injection. The nicotine rewarding effects on mice were examined on day 31 using the CPP test. Con, mice treated with physiological saline; Nic, mice treated with nicotine $\left(0.5 \mathrm{mg} \mathrm{kg}^{-1} \mathrm{~d}^{-1}\right)$; Th- $\mathrm{L}(\mathrm{N})$, mice treated with nicotine and L-theanine $\left(250 \mathrm{mg} \mathrm{kg}^{-1} \mathrm{~d}^{-1}\right)$; Th-H $(\mathrm{N})$, mice treated with nicotine and L-theanine $\left(500 \mathrm{mg} \mathrm{kg}^{-1} \mathrm{~d}^{-1}\right)$; DHßE $(\mathrm{N})$, mice treated with nicotine and DHßE; Th (N-), mice that had already developed rewarding effects in response to nicotine were treated with L-theanine (500 $\mathrm{mg} \mathrm{kg}^{-1} \mathrm{~d}^{-1}$ ) alone (nicotine abstinence). The results are presented as mean \pm SEM, $n=8$. * $P<0.05$ compared with control group; \#, $P<0.05$ compared with nicotine group.

suggesting that both dosages of L-theanine and $\mathrm{DH} \beta \mathrm{E}$ pre-treatment inhibited the CPP formation induced by nicotine. To further test whether L-theanine treatment reduces the CPP that has been already formed, mice were first injected with nicotine $\left(0.5 \mathrm{mg} \mathrm{kg}^{-1} \mathrm{~d}^{-1}\right.$, s.c.) for $14 \mathrm{~d}$ to induce the CPP preference, then treated with L-theanine alone (without nicotine), or injected with nicotine unceasingly with simultaneous pre-treatment of L-theanine or DH $\beta E$. The results showed that $\mathrm{DH} \beta \mathrm{E}$ as well as L-theanine treatment attenuated the preference of mice for the drug-paired compartment that had already been induced by nicotine (Figure 1C). These data suggest that L-theanine can reduce the nicotine-induced rewarding effects both before and after the rewarding effects have been developed.

\subsection{L-theanine inhibits the excitatory status of SH- SY5Y cells induced by nicotine}

Nicotine has been shown to activate cells and lead to their excitatory status [11]. The excitability of dopaminergic neurons induced by nicotine is considered part of the mechanism for the rewarding effects of nicotine [25]. Glucose is the key molecule of energy metabolism in cells and its uptake is an indicator of the excitatory status of the cells. Therefore, we next studied the effect of L-theanine on the nicotine-induced excitatory status of SH-SY5Y cells by assessing the glucose uptake of cells using the fluorescent probe 2-NBDG. As shown in Figure 2, the fluorescent signal intensity in SH-SY5Y cells increased significantly after nicotine treatment, indicating that nicotine-induced excita- 

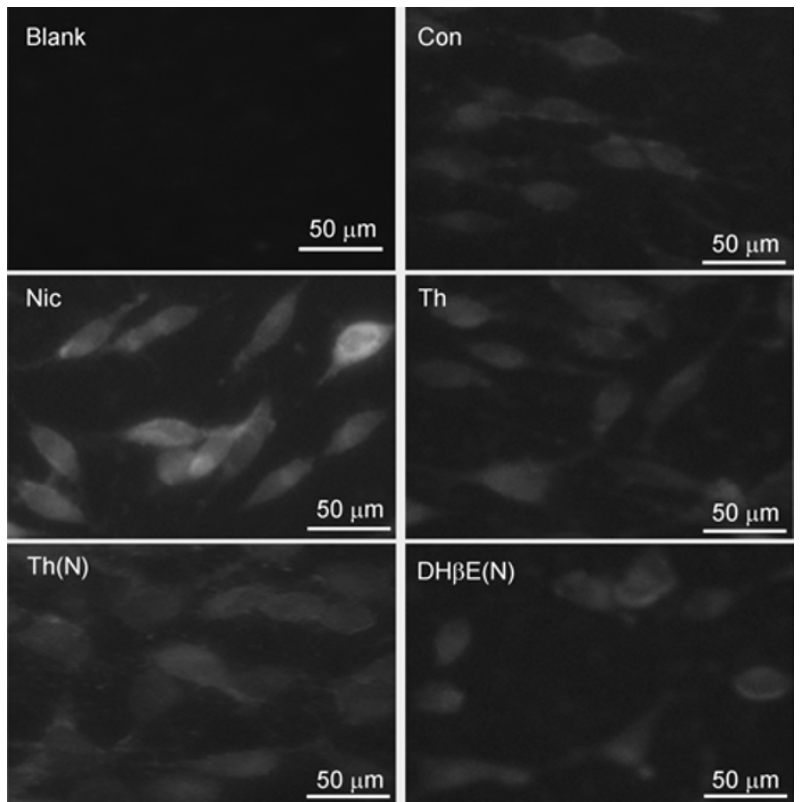

Figure 2 Effects of L-theanine and nicotine on glucose uptake in SH-SY5Y cells. A, Glucose uptake was measured using the 2-NBDG probe and fluorescence microscopy. Blank, cells without 2-NBDG; Con, cells treated with phosphate buffered saline (PBS) and measured using the 2-NBDG probe; Nic, cells treated with nicotine, PBS and measured using the 2-NBDG probe; Th, cells treated with L-theanine, PBS and measured using the 2-NBDG probe; Th(N), cells treated with nicotine, L-theanine, PBS measured using the 2-NBDG probe; $\mathrm{DH} \beta E(\mathrm{~N})$, cells treated with nicotine, DH $\beta E$, PBS and measured using the $2-N B D G$ probe. $B$, Statistical analysis results from the fluorescence in (A). The data were expressed as the mean of ratio \pm SEM, $n=3$. * $P<0.05$ compared with control group; \#, $P<0.05$ compared with nicotine group.

tory status and glucose uptake were increased in cells. When cells were pre-treated with L-theanine or the inhibitor of the nicotine receptor $(\mathrm{DH} \beta \mathrm{E})$, the fluorescence intensity of cells reduced significantly when compared with cells treated with nicotine alone $(P<0.05)$ (Figure 2). These data indicated that the nicotine-induced excitatory status of SH-SY5Y cells was inhibited by L-theanine.

\subsection{L-theanine inhibits the upregulation of tyrosine hydroxylase (TH) expression and dopamine levels in the mouse midbrain}

The increase of dopamine release is an important reward process caused by nicotine [20,21]. We next examined whether L-theanine had any effect on the DA release induced by nicotine in mice. The results showed that levels of dopamine in the midbrain increased significantly after two weeks of nicotine treatment, while pretreatment with the inhibitor of the nicotine receptor $(\mathrm{DH} \beta \mathrm{E})$ or L-theanine inhibited this increase $(P<0.05)$ (Figure 3$)$.

$\mathrm{TH}$ is a key enzyme responsible for the synthesis of dopamine. Immunohistochemical staining of $\mathrm{TH}$ showed that the number of TH-positive neurons was significantly increased following nicotine treatment, whereas this increase

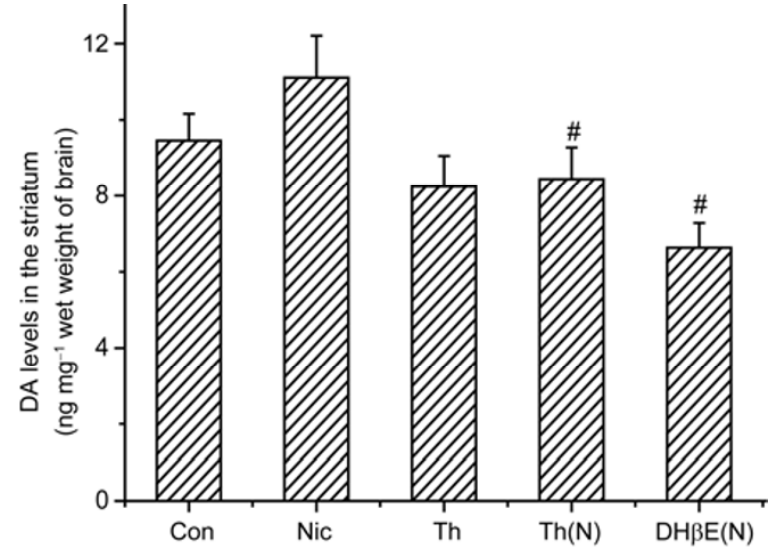

Figure 3 Effects of L-theanine on the nicotine-induced increase of dopamine (DA) in the midbrain. The DA levels in the mouse midbrain were measured by high performance liquid chromatography with electrochemical detection. Con, mice were treated with physiological saline; Nic, mice were treated with nicotine; Th, mice were treated with L-theanine $(500 \mathrm{mg}$ $\mathrm{kg}^{-1} \mathrm{~d}^{-1}$, s.c.); Th(N), mice were treated with nicotine and L-theanine (500 $\left.\mathrm{mg} \mathrm{kg}^{-1}\right) ; \mathrm{DH} \beta \mathrm{E}(\mathrm{N})$, mice were treated with nicotine and $\mathrm{DH} \beta \mathrm{E}$. The data were expressed as the mean of ratio \pm SEM, $n=3$. \#, $P<0.05$ compared with nicotine group.

was blocked in the brains of L-theanine pretreated animals (Figure 4A). Meanwhile, western blotting showed that the expression of TH in the ventral tegmental area (VTA) increased significantly after nicotine treatment when compared with the control group, while pre-treatment with L-theanine reduced the expression of $\mathrm{TH}$ in a dosedependent manner. As shown in Figure 4, L-theanine treatment alone did not affect the production of dopamine in the midbrain and the expression of TH in the VTA, suggesting that the inhibitory effects of L-theanine on the production of DA and the expression of TH in mice only occurred when mice were stimulated by nicotine.

\subsection{L-theanine inhibits the expression of the $\alpha_{4}, \beta_{2}$ and $\alpha_{7} \mathbf{n A C h R s}$ subunits induced by nicotine in the reward circuit related areas of the mouse brain}

To dissect the mechanisms by which L-theanine inhibits the rewarding effects induced by nicotine, we next examined the expression of the $\alpha_{4}, \beta_{2}$ and $\alpha_{7}$ nAChR subunits in the reward circuit related areas of the mouse brain (VTA, PFC and NAc) following different treatments using Western blotting. Our results revealed that the expression of these three forms of nAChR subunits in these three areas increased significantly after treatment with nicotine $(P<0.05)$. When mice were pre-treated with L-theanine, the upregulation of the $\alpha_{4}$ and $\beta_{2}$ nAChR subunits were inhibited in the VTA, PFC and NAc, and the upregulation of the $\alpha_{7}$ nAChR subunit induced by nicotine were inhibited in the VTA and PFC but not in the NAc. The effects of L-theanine treatment alone on the expression of $\alpha_{4}, \beta_{2}$ and $\alpha_{7} \mathrm{nAChR}$ in the VTA, $\mathrm{PFC}$ and NAc areas were examined in mice that were not 

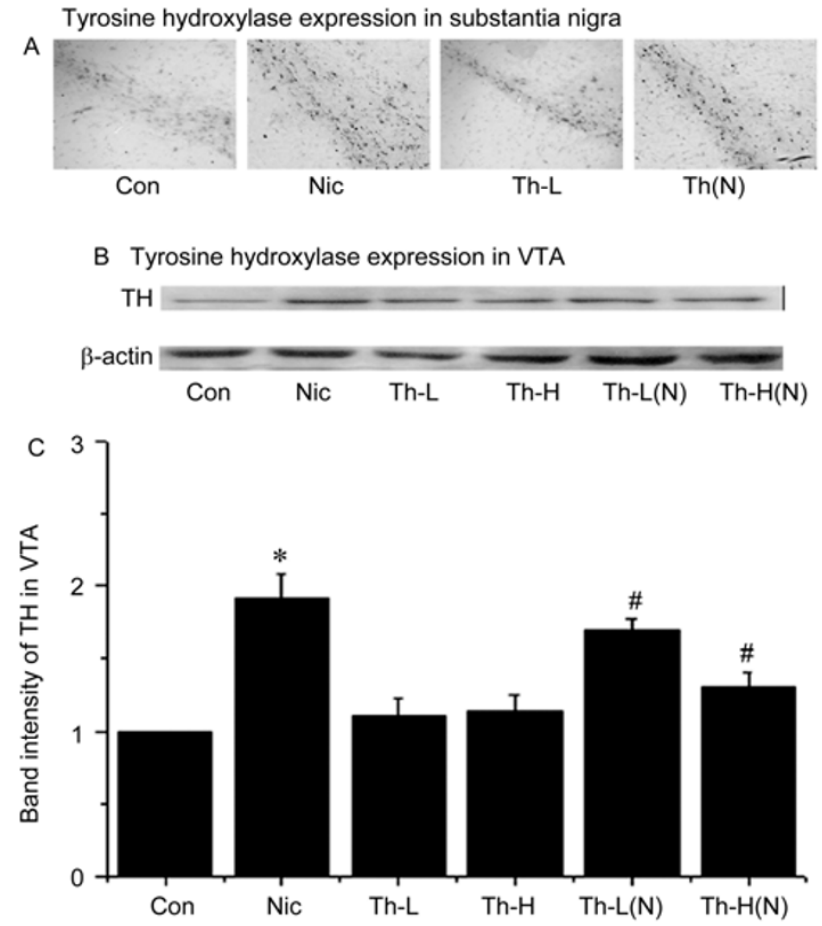

Figure 4 Effects of L-theanine on the nicotine-induced expression of tyrosine hydroxylase (TH) in the mouse brain. A, Immunohistochemical staining of tyrosine hydroxylase in the mouse substantia nigra. A1, The quantification results of immunohistochemical staining from 3 independent experiments. B, Effects of L-theanine on the expression of tyrosine hydroxylase $(\mathrm{TH})$ analyzed by western blotting in the ventral tegmental area (VTA). B1, The quantification results of TH expression in the VTA from 3 independent experiments. Con, mice were treated with physiological saline; Nic, mice were treated with nicotine; Th-L, mice were treated with L-theanine $\left(250 \mathrm{mg} \mathrm{kg}^{-1}\right)$; Th- $\mathrm{H}$, mice were treated with L-theanine $(500$ $\left.\mathrm{mg} \mathrm{kg}^{-1}\right)$; Th-L(N), mice were pre-treated with L-theanine $\left(250 \mathrm{mg} \mathrm{kg}^{-1}\right)$ then were treated with nicotine; Th(N), Th-H(N), mice were pre-treated with L-theanine $\left(500 \mathrm{mg} \mathrm{kg}^{-1}\right)$ then were treated with nicotine. The data were expressed as the mean of ratio \pm SEM, $n=3$. *, $P<0.05$ compared with control group; \#, $P<0.05$ compared with nicotine group.

treated with nicotine. L-theanine treatment alone only affected the expression of the $\alpha_{4}$ nAChR subunit, which decreased in the NAc (Figure $5 \mathrm{~A}-\mathrm{C}, \mathrm{A} 1-\mathrm{C} 1$ ). These data suggested that the L-theanine-induced downregulation of $\alpha_{4}$, $\beta_{2}$ and $\alpha_{7} \mathrm{nAChR}$ subunit expression in the three reward circuit-related areas primarily happened when mice were stimulated by nicotine.

\subsection{L-theanine inhibits nicotine-induced c-Fos expres- sion in the reward circuit related areas of the mouse brain}

Addictive substance abuse may induce neuron-specific adaptation and lead to physical and psychological dependence $[25,26]$. Recent investigations indicate that changes in c-Fos may play a crucial role in nicotine addiction [26]. Our study showed that the expression of c-Fos was upregulated in the three reward circuit related areas of mice after treatment with nicotine, while this phenomenon was inhibited after pretreatment with L-theanine (Figure 6). Meanwhile, double-immunofluorescence staining showed that both $\mathrm{TH}$ and c-Fos expression were co-localized and upregulated in SH-SY5Y cells after treatment with nicotine, while these nicotine-stimulated effects were inhibited by L-theanine pretreatment (Figure 7).

\subsection{Knockdown of c-Fos inhibits the excitatory status of the cell but not the upregulation of TH induced by nicotine in SH-SY5Y cells}

To study the importance of c-Fos in the nicotine-induced excitatory status of cells, we performed c-Fos siRNA experiments in SH-SY5Y cells and measured glucose intake using the 2-NBDG assay. As shown in Figure 8A and B, the expression of c-Fos decreased by $47 \%$ following c-Fos siRNA treatment. Meanwhile, glucose uptake induced by nicotine decreased significantly in cells treated with c-Fos siRNA $(P<0.05$; Figure $8 \mathrm{C})$. This indicated that knockdown of c-Fos inhibited the excitatory status of cells. However, the expression of $\mathrm{TH}$ induced by nicotine was not changed by c-Fos siRNA treatment (Figure $8 \mathrm{~A}$ and $\mathrm{B}$ ).

\section{Discussion}

In this study, we found that L-theanine, an amino acid derivative of tea, reduced the nicotine-induced rewarding effects in a mouse CPP model and inhibited the nicotine-induced excitatory status of SH-SY5Y cells. The inhibitory effect of L-theanine was as effective as the inhibitor of the nicotine receptor $(\mathrm{DH} \beta \mathrm{E})$. This is in accordance with previous findings that reveal L-theanine had an antagonistic effect on the excitement induced by caffeine [16].

The increase in TH expression and dopamine release are important factors in the development of the rewarding effects of nicotine [27,28]. In our experiments, it was found that $\mathrm{TH}$ expression increased significantly after treatment with nicotine in the mouse midbrain, while it was inhibited after pretreatment with L-theanine. Interestingly, TH expression was not different between rats treated with L-theanine alone and the control group (Figure 4). These data suggest that the inhibitory effects of L-theanine on the production of dopamine and the expression of $\mathrm{TH}$ in mice only occurred when mice were stimulated with nicotine.

Mounting data indicates that the increase in the number of $\alpha_{4}, \beta_{2}$ and $\alpha_{7}$ nAchRs and their activation play a crucial role in the rewarding effects of nicotine[10-12]. Nicotine-seeking behavior was observed to decrease when the function of the nicotine receptors and their related pathways were inhibited [29,30]. Thus, nicotine receptors are responsible for nicotine addiction. Our present data showed that expression of $\alpha_{4}, \beta_{2}$ and $\alpha_{7}$ nAChR subunits increased significantly after treatment with nicotine in the reward circuit-related areas of mice. It has been shown previously that 
A nAChRs expression in ventral tegmental Area (VTA) $\mathrm{nAChR} \alpha_{4} \longrightarrow--\square$
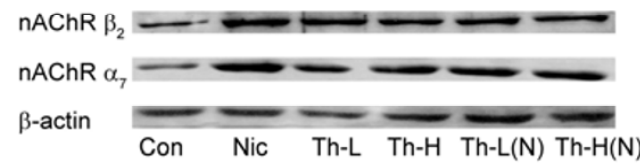

B nAChRs expression in prefrontal cortex (PFC)
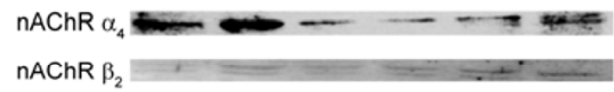

$\mathrm{nAChR} \alpha_{7} \longrightarrow--\longrightarrow$

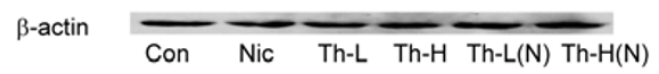

C nAChRs expression in nuclaus accubens (NAc)
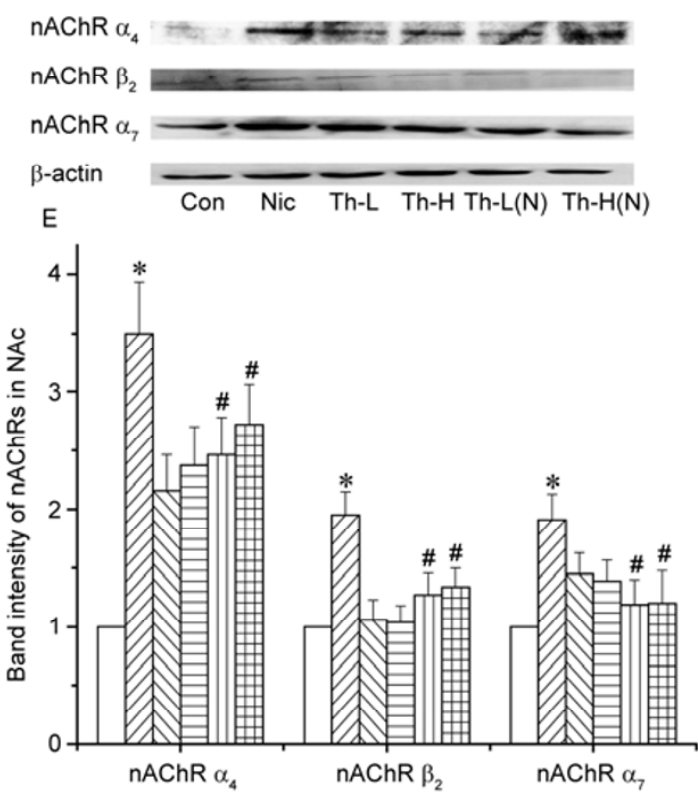
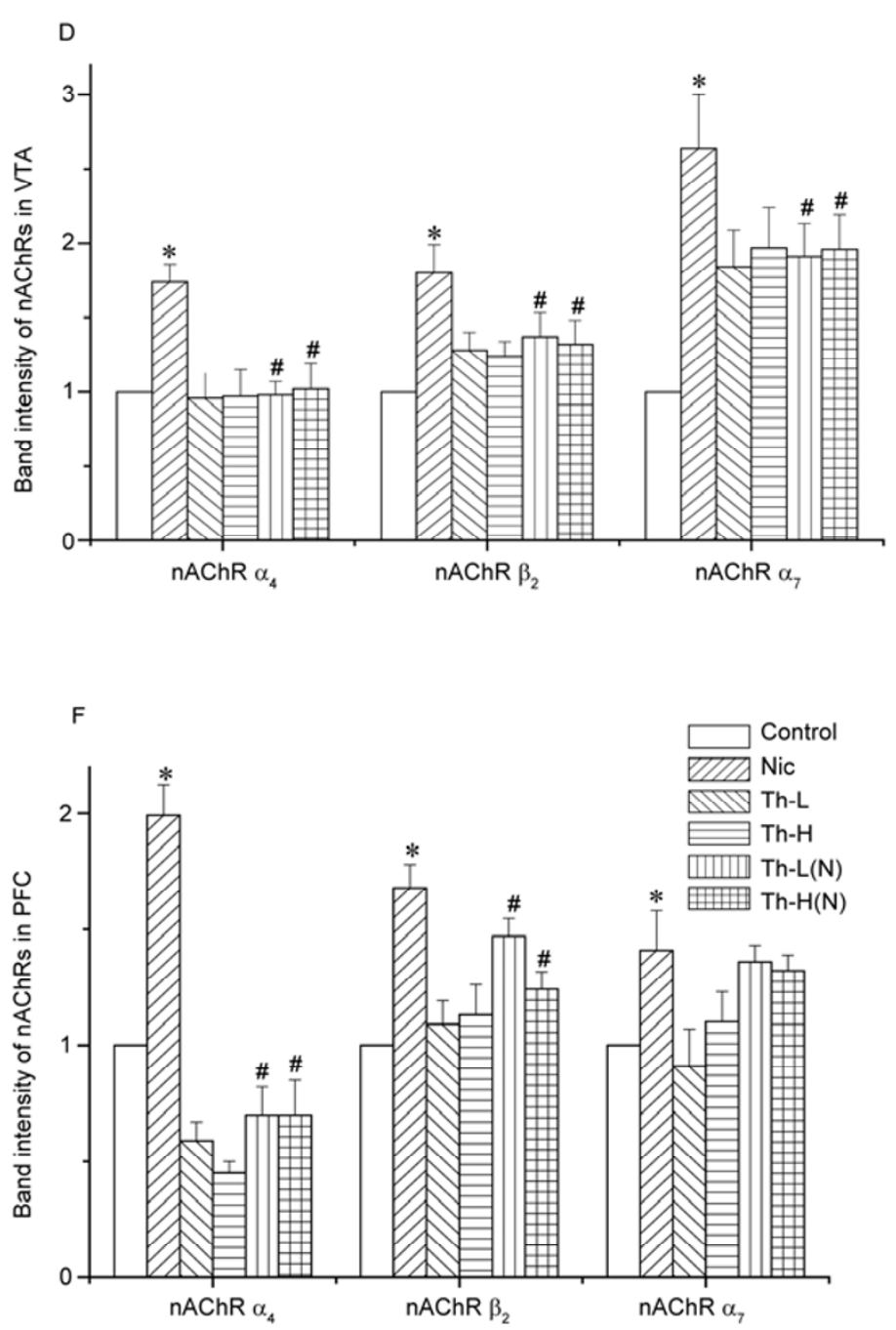

Figure 5 Effects of L-theanine on the expression of the nicotine receptor (nAChR) in the mouse brain. Protein extracts prepared from different parts of mouse brain were analyzed using Western blotting. The expression of nAChR was examined in the ventral tegmental area (VTA) (A), prefrontal cortex (PFC) (B) and nuclear accumbens core (NAc). C, The quantification results of nAChR expression in the VTA (A1), PFC (B1) and NAc (C1) from 3 independent experiments. Con, mice were treated with physiological saline; Nic, mice were treated with nicotine; Th-L, mice were treated with $\mathrm{L}_{-}$theanine $\left(250\right.$ mg $\left.\mathrm{kg}^{-1}\right)$; $\mathrm{Th}-\mathrm{H}$, mice were treated with L-theanine $\left(500 \mathrm{mg} \mathrm{kg}^{-1}\right)$; Th-L(N), mice were pre-treated with $\mathrm{L}$-theanine $\left(250 \mathrm{mg} \mathrm{kg}^{-1}\right)$ then were treated with nicotine; $\mathrm{Th}-\mathrm{H}(\mathrm{N})$, mice were pre-treated with L-theanine $\left(500 \mathrm{mg} \mathrm{kg}^{-1}\right)$ then were treated with nicotine. The data were expressed as the mean of the ratio \pm SEM, $n=3$. *, $P<0.05$ compared with control group; \#, $P<0.05$ compared with nicotine group.

prolonged nicotine exposure causes the functional desensitization of the nicotine-sensitive nAChRs [31-34], as a result, nAChR expression is upregulated while tolerance of nAChRs to nicotine increases. This is consistent with our results that the expression of the nAChRs was upregulated in the reward circuit-related areas of mice after nicotine treatment. Our data also showed that L-theanine pretreatment inhibited the nicotine-induced upregulation of $\alpha_{4}, \beta_{2}$ nAChR subunits in the VTA, PFC and NAc, and the $\alpha_{7}$ nAChR subunit in the VTA and NAc. This is a specific process of the nAChRs, which causes the upregulation of the nAChR. The expression of the above nAChR subunits were not downregulated in these three reward circuit-related areas of mice by L-theanine treatment alone, except for the expression $\alpha_{4}$ nAChR, which was found to decrease in the NAc. These data suggest that the inhibitory effects of L-theanine on the expression of $\alpha_{4}, \beta_{2}$ and $\alpha_{7}$ nAChR subunits in the reward circuits primarily occurred when mice were stimulated with nicotine. Overall, the data indicates that L-theanine may inhibit midbrain dopamine production through inhibiting the nicotine-induced upregulation of the $\alpha_{4}, \beta_{2}$ and $\alpha_{7}$ nAChR subunits in the reward circuits, thus inhibiting the rewarding effects. However, it is unclear how L-theanine inhibits the nicotine-induced upregulation of nAChR subunit expression, for example, whether Ltheanine inhibits nicotine through competitive or uncompetitive binding to the receptors. This area requires further investigation. 


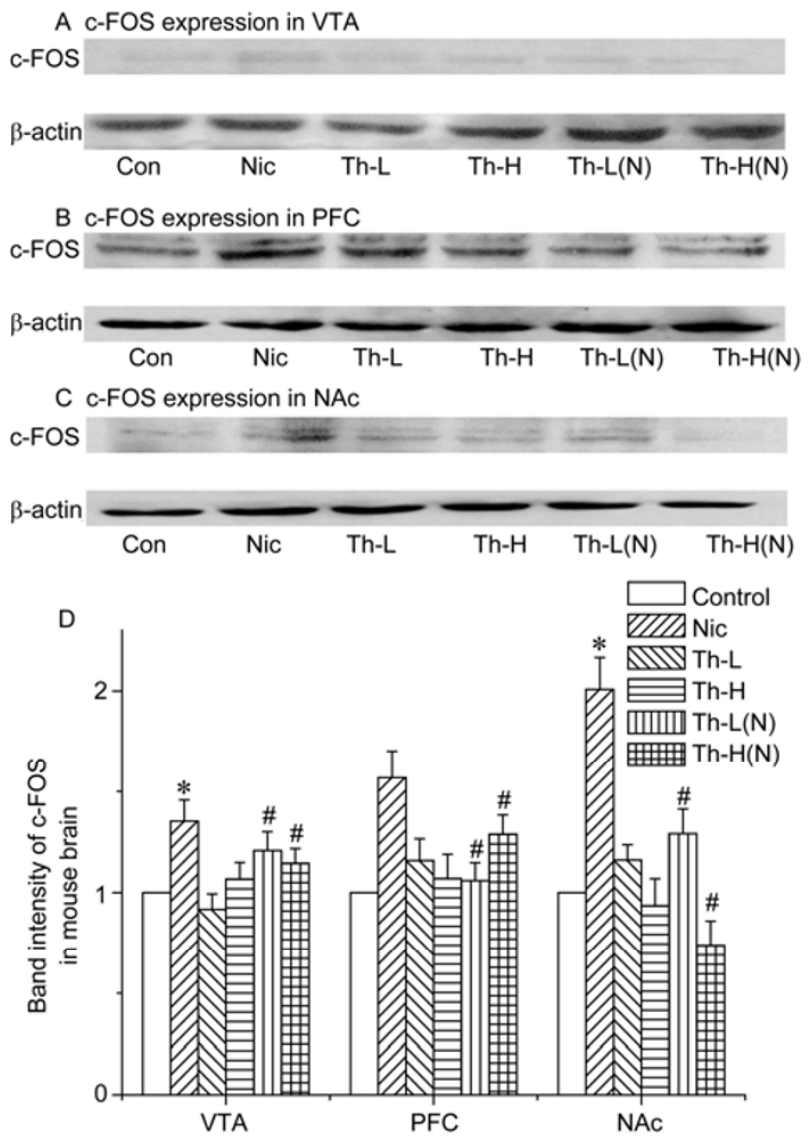

Figure 6 Effects of L-theanine on the expression of c-Fos in the mouse brain. Protein extracts prepared from different parts of mouse brain were analyzed using Western blotting. The expression of c-Fos was examined in the ventral tegmental area (VTA) (A), prefrontal cortex (PFC) (B), and nuclear accumbens core (NAc) (C). D, The quantification results of c-Fos expression in the VTA, PFC and NAc from 3 independent experiments. Con, mice were treated with physiological saline; Nic, mice were treated with nicotine; Th-L, mice were treated with L-theanine $\left(250 \mathrm{mg} \mathrm{kg}^{-1}\right)$; $\mathrm{Th}-\mathrm{H}$, mice were treated with L-theanine $\left(500 \mathrm{mg} \mathrm{kg}^{-1}\right)$; Th-L(N), mice were pre-treated with L-theanine $\left(250 \mathrm{mg} \mathrm{kg}^{-1}\right)$ and then with nicotine; $\mathrm{Th}-\mathrm{H}(\mathrm{N})$, mice were pretreated with L-theanine $\left(500 \mathrm{mg} \mathrm{kg}^{-1}\right)$ and then with nicotine. The data were expressed as the mean of the ratio \pm SEM, $n=3$. $*, P<0.05$ compared with control group; \#, $P<0.05$ compared with nicotine group.

As a member of the fos transcription factor family, c-Fos has been shown to be associated with the neuron-specific adaptation induced by nicotine [14,26]. The expression of c-Fos increased significantly in the reward circuit-related areas after acute treatment with nicotine $[35,36]$. Moreover, the expression of c-Fos increased significantly in the NAc after nicotine was injected into the VTA directly [26]. In our study, the expression of c-Fos was upregulated in the three reward circuit-related areas by nicotine treatment, while this phenomenon was inhibited by L-theanine pre-treatment (Figure 6). In SH-SY5Y cells, doubleimmunofluorescence staining revealed that the expression of c-Fos and TH increased significantly in the same cells after nicotine treatment. This effect of nicotine was inhibit-

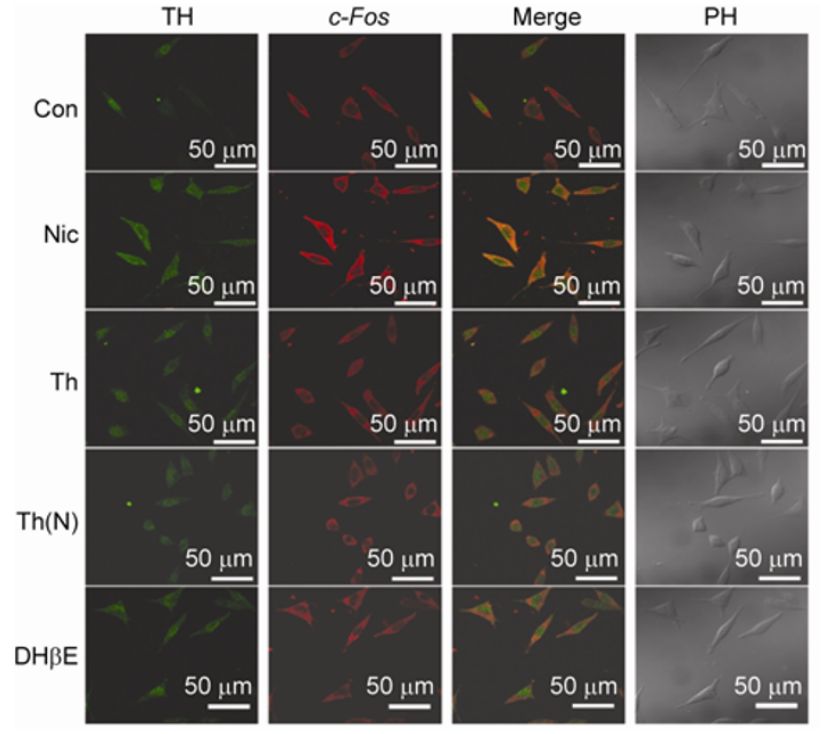

Figure 7 Effects of L-theanine on tyrosine hydroxylase (TH) and c-Fos expression examined by immunofluorescence staining. SH-SY5Y cells were treated and double-immunofluorescence staining was performed as described in Methods. Fluorescence was examined under a confocal laser scanning microscope (LSCMFV500). TH, TH immunostaining (green); c-Fos, c-Fos immunostaining (red); Merge, double-immunostaining of TH and c-Fos (yellow); PH, cell optical micrograph. Con, cells were treated with physiological saline; Nic, cells were treated with nicotine; Th, cells were treated with L-theanine $\left(100 \mu \mathrm{mol} \mathrm{L} \mathrm{L}^{-1}\right)$; Th(N), cells were treated with nicotine and L-theanine $\left(100 \mu \mathrm{mol} \mathrm{L}^{-1}\right) ; \mathrm{DH} \beta \mathrm{E}(\mathrm{N})$, cells were treated with nicotine and $\mathrm{DH} \beta \mathrm{E}$.

ed by L-theanine pre-treatment (Figure 7). The data suggest that the inhibitory effects of L-theanine on nicotine-induced c-Fos expression may contribute to the regulation of L-theanine on nicotine-induced neuron-specific adaptation. We found that knock-down of c-Fos inhibited the nicotine-induced excitatory status of cells but not the expression of $\mathrm{TH}$ (Figure 8A and A1), indicating that the effect of c-Fos on the excitatory status of cells and neuron-specific adaptation induced by nicotine was not mediated by the regulation of $\mathrm{TH}$ expression.

The binding sites of the ${ }^{3} \mathrm{H}$ nicotine in the central nervous system as well as the number of cells that can react to nicotine were increased after prolonged nicotine exposure [37,38]. Our present study indicates that L-theanine can inhibit the rewarding effects in the mouse CPP model and reduce the excitatory status of cells induced by nicotine. The inhibitory effects of L-theanine may be achieved by a complex mechanism. First, L-theanine can inhibit the nicotine-induced up-regulation of the $\alpha_{4}, \beta_{2}$ and $\alpha_{7} \mathrm{nAChR}$ subunits in regions that are related to the dopamine reward pathway and decrease the number of cells that can react to nicotine. Second, L-theanine can inhibit the nicotine-induced upregulation of dopamine production in the midbrain. Third, L-theanine can inhibit nicotine-induced expression of c-Fos in the regions that are related to the dopamine reward pathway, ultimately inhibiting the re- 


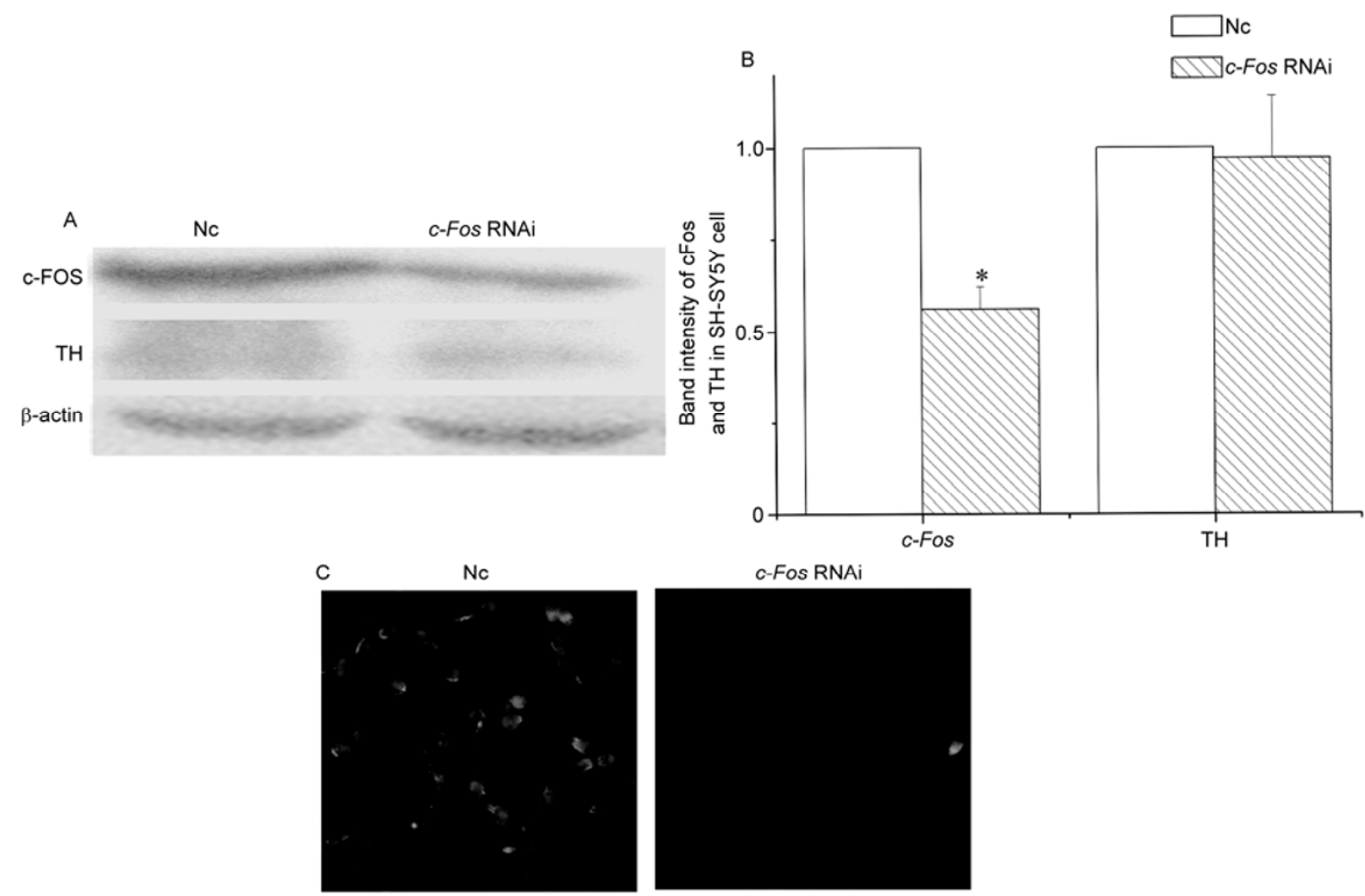

Figure 8 Effects of c-Fos knockdown on the expression of TH and glucose uptake in SH-SY5Y cells. A, c-Fos and TH expression levels after c-Fos knockdown. Protein extracts prepared from SH-SY5Y cells were analyzed using Western blotting. B, The quantification results of c-Fos and TH expression from 3 independent experiments. C, Glucose uptake status in SH-SY5Y cells induced by nicotine after c-Fos knockdown. D, Quantification results of fluorescence from 3 independent experiments. Nc, siRNA-Control; c-Fos RNAi, siRNA-c-Fos; The data were expressed as the mean of the ratio \pm SEM, $n=3$. *, $P<0.05$ compared with control group.

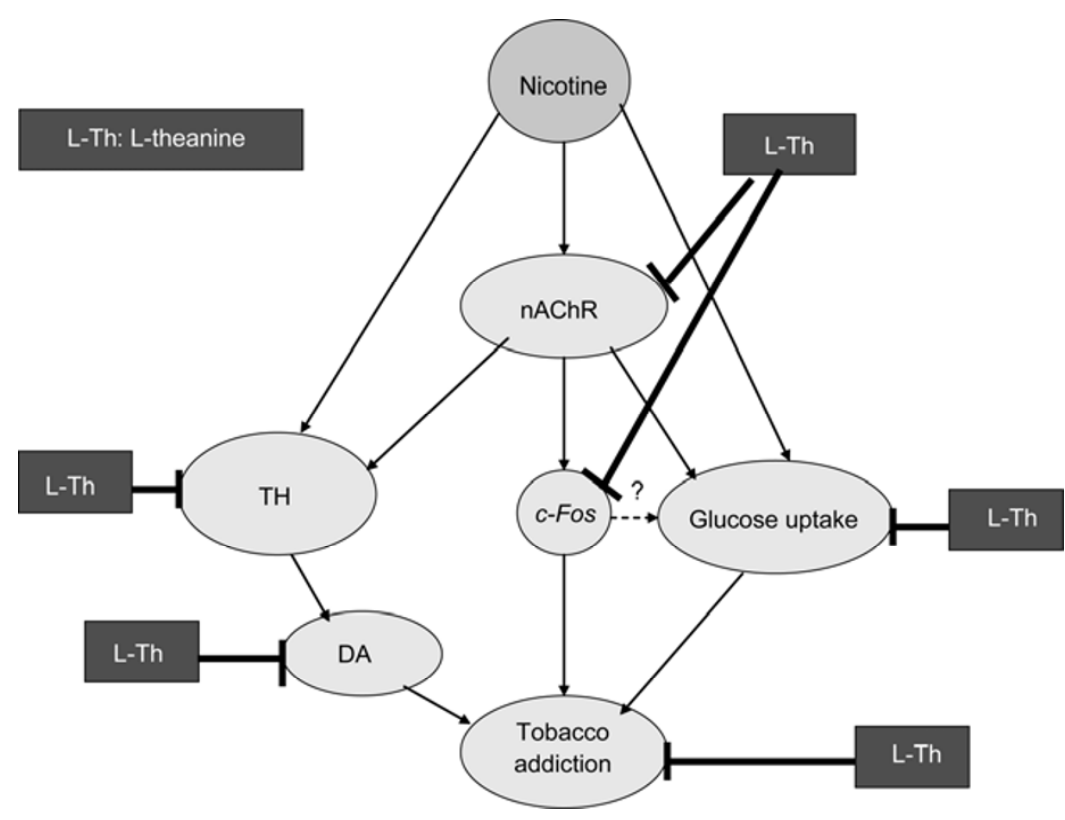

Figure 9 Schematic diagram: L-theanine inhibits nicotine-induced dependence through inhibiting the nAChR-dopamine reward pathway.

warding effects and the neuron-specific adaptation induced by nicotine (Figure 9 ).

Smoking cessation is the ultimate method for reducing smoking-related diseases. However, quitting smoking is extremely difficult because of the addictive nature of nicotine. Future application of L-theanine in smoking cessation 
may provide an alternative therapeutic strategy for smokers to reduce and/or quit smoking by inhibition of nicotine dependence [39-43].

Some studies have suggested nicotine as a therapy for Alzheimer's disease (AD) and Parkinson's disease (PD) [44-49]; however, the dependence of nicotine limits the use of nicotine as a medication. Interestingly, L-theanine has been shown to have some benefits for the prevention and treatment of AD [50]. Thus, L-theanine may have a synergic effect with nicotine for AD therapy, and a combination of L-theanine and nicotine may prevent nicotine dependence, opening up new possibilities for novel therapeutics for neurodegenerative disorders such as AD and PD.

Overall, the present study showed that L-theanine reduced the nicotine-induced rewarding effects via inhibition of the nAChR-dopamine reward pathway. These results may offer new therapeutic strategies for the treatment of tobacco addiction.

This work was partly supported by the National Natural Science Foundation of China (Grant No. 30870587) and National Basic Research Program of China from the Department of Science and Technology of China (Grant No. 2006CB500700).

1 Gu D F, Kelly T N, Wu X, et al. Mortality attributable to smoking in China. N Engl J Med, 2009, 360: 150-159

2 McLellan A T, Lewis D C, O'Brien C P, et al. Drug dependence, a chronic medical illness: implications for treatment, insurance, and outcomes evaluation. JAMA, 2000, 284: 1689 -1695

3 Mizoue T, Tokui N, Nishisaka K. Prospective study on the relation of cigarette smoking with cancer of the liver and stomach in an endemic region. Intern J Epidem, 2000, 29: 232-237

4 Oncken C, Gonzales D, Nides M, et al. Efficacy and safety of the novel selective nicotinic acetylcholine receptor partial agonist, varenicline, for smoking cessation. Arch Intern Med, 2006, 166: 1571-1577

5 Ray R, Schnoll R A, Lerman C. Nicotine dependence: biology, behavior, and treatment. Annu Rev Med, 2009, 60: 247-260

6 Rigotti A N. Treatment on tobacco use and dependence. N Engl J Med, 2002, 346: 506-512

7 Moxham J. Nicotine addiction. BMJ, 2000, 7232: 391-392

8 Picciotto M R, Zoli M, Rimondini R. Acetyl-choline receptors containing the $\beta 2$ subunit are involved in the reinforcing properties of nicotine. Nature, 1998, 6663: 173-177

9 Tapper A R, McKinney S L, Nashmi R. Nicotine activation of $\alpha 4^{*}$ receptors: sufficient for reward, tolerance, and sensitization. Science, 2004, 306: 1029-1032

10 Bencherif M, Fowler K, Lukas R J. Mechanisms of up-regulation of neuronal nicotinic acetylcholine receptors in clonal cell lines and primary cultures of fetal rat brain. J Pharmacol Exp Ther, 1995, 275: 987-999

11 Peng X, Gerzanich V, Anand R. Nicotine-induced increase in neuronal nicotinic receptors results from a decrease in the rate of receptor turnover. Mol Pharmacol, 1994, 46: 523-530

12 Breese C R, Marks M J, Logel J. Effect of smoking history on ${ }^{3} \mathrm{H}$ nicotine binding in human postmortem brain. J Pharmacol Exp Ther, 1997, 282: 7-13

13 Besson M, Granon S, Mameli-Engvall M. Long-term effects of chronic nicotine exposure on brain nicotinic receptors. Proc Natl Acad Sci USA, 2007, 104: 8155-8160

14 Nestler E J. Molecuhr mechanisms of drug addiction. Neu ropharm, 2004, 47: 24-32
15 Eschenauer G, Sweet B V. Pharmacology and therapeutic uses of theanine. Am J Health-Syst Ph, 2006, 63: 26-30

16 Yan J Q, Di X J, Liu C Y, et al. Cessation effect of tea filter on cigarette smoking addiction. Sci China Life Sci, 2010, 53: 533-541

17 Nguyen H N, Rasmussen B A, Perry D C. Subtypeselective up-regulation by chronic nicotine of high-affinity nicotinic receptors in rat brain demonstrated by receptor autoradiography. J Pharmacol Exp Ther, 2003, 307: 1090-1097

18 Huang E Y, Liu T C, Tao P L. Co-administration of dextromethorphan with morphine attenuates morphine rewarding effect and related dopamine releases at the nucleus accumbens. NaunynSchmiedebergs Arch Pharmacol, 2003, 368: 386-392

19 Laviolette S R, Nader K, Kooy D V. Motivational state determines the functional role of the mesolimbic dopamine system in the mediation of opiate reward processes. Behav Brain Res, 2002, 129: 17-29

20 Jiang H, Luan Z, Wang J, et al. Neuroprotective effects of iron chelator desferal on dopaminergic neurons in the substantia nigra of rats with iron-overload. Neurochem Int, 2006, 49: 605-609

21 Shachar B D, Youdim M B. Selectivity of melaninized nigra-striatal dopamine neurons to degeneration in Parkinson's disease may depend on iron \pm melanin interaction. J Neural Transm Suppl, 1990, 29: 251-255

22 Bezard E, Dovero S, Bioulac B, et al. Kinetics of nigral degeneration in a chronic model of MPTP-treated mice. Neurosci Lett, 199, 234: 43-45

23 Gross C E, Ravenscroft P, Dovero S, et al. Pattern of levodopa-induced striatal changes is different in normal and MPTP-lesioned mice. J Neurochem, 2003, 84: 1246-1251

24 Miller R G. Simultaneous Statistical Inference. New York: Springer, 1981. 230

25 Mansvelder H D, Keath J R, McGehee D S. Synaptic mechanisms underlie nicotine-induced excitability of brain reward areas. Neuron, 2002, 33: 905-919

26 Panagis G, Nisell M, Nomikos G G. Nicotine injections into the Ventral tegmental area increase locomotion and Fos-like immunoreactivity in the nucleus ac-cumbens of the rat. Brain Res, 1996, 730: 133-142

27 Rahman S, Zhang J, Corrigall W A. Effects of acute and chronic nicotine on somatodendritic dopamine release of the rat ventral tegmental area: in vivo microdialysis. Neurosci Lett, 2003, 348: 61-64

28 Ferrafi R, Le Novere N, Picciotto M R. Acute and long-term changes in the mesolimbic dopamine pathway after systemic or local single nicotine injections. Eur J Neurosci, 2002, 15: 1810-1818

29 Corrigall W A, Coen K M, Adamson K L. Self-administered nicotine activates the mesolimbic dopamine system through the ventral tegmental area. Brain Res, 1994, 653: 278-284

30 Markou A, Paterson N E. The nicotinic antagonist methyllycaconitine has differential effects on nicotine self-administration and nicotine withdrawal in the rat. Nicotine Tob Res, 2001, 3: 361-373

31 Lapchak P A, Araujo D M, Quirion R. Effect of chronic nicotine treatment on nicotinic autoreceptor function and $\mathrm{N}-\left[{ }^{3} \mathrm{H}\right]$ methylcarbamylcholine binding sites in the rat brain. J Neurochem, 1989, 52: 483-491

32 Lapin E P, Maker H S, Sershen H. Action of nicotine on accumbens dopamine and attenuation with repeated administration. Eur J Pharmacol, 1989, 160: 53-59

33 Marks M J, Burch J B, Collins A C. Effects of chronic nicotine infusion on tolerance development and nicotinic receptors. J Pharmacol Exp Ther, 1983, 226: 817-825

34 Sharp B M, Beyer H S, Levine A S. Attenuation of the plasma prolactin response to restraint stress after acute and chronic administration of nicotine to rats. J Pharmacol Exp Ther, 1987, 241: 438-442

35 Shram M J, Funk D, Li Z. Acute nicotine enhances c-FOS mRNA expression differentially in reward-related substrates of adolescent and adult rat brain. Neuro Sci, 2007, 418: 286-291

36 Salminen O, Seppa T, Gaddnas H. The effects of acute nicotine on the metabolism Of dopamine and the expression of Fos protein in striatal and limbic brain areas of rats during Chronic nicotine infusion 
and its withdrawal. J Neuro Sci, 1999, 19: 8145-8151

37 Marks M J, Grady S R, Yang J M. Desensitization of nicotine-stimulated ${ }^{86} \mathrm{Rb}+$ efflux from mouse brain synaptosomes. $\mathrm{J}$ Neurochem, 1994, 63: 2125-2135

38 Schwartz R D. Nicotinic cholinergic receptor binding sites in the brain: regulation in vivo. Science, 1983, 220: 214-216

39 Benwell M E M, Balfour D J K. The effects of acute and repeated nicotine treatment on nucleus accumbens dopamine and locomotor activity. Br J Pharmacol, 1992, 105: 849-856

40 Balbani A P S, Montovani J C. Methods for smoking cessation and treatment of nicotine dependence. Rev Bras Otorrinolaringol, 2005, 71: $820-826$

41 Ray R, Schnoll R A, Lerman C. Nicotine dependence: biology, behavior, and treatment. Annu Rev Med, 2009, 60: 247-260

42 Rigotti A N. Treatment on tobacco use and dependence. N Engl J Med, 2002, 346: 506-512

43 Peng R L, Wang S L. Nicotine sublingual tablet for smoking cessation in 115 cases: a double-blind randomized placebo-controlled clinical trial. J Clin Rehabilit Tissue Engin Res, 2007, 11: 10443-10446
44 Liu Q, Tao Y, Zhao B L. ESR study on scavenging effect of nicotine on free radicals. Appl Mag Reson, 2003, 24: 105-112

45 Liu Q, Zhao B L. Nicotine attenuates $\beta$-amyloid peptide induced neurotoxicity, free radical and calcium accumulation in hippocampal neuronal cultures. Brit J Pharmoco, 2004, 1141: 746-754

46 Xie Y X, Bezard E, Zhao B L. Unraveling the receptor-independent neuroprotective mechanism in mitochondria. J Biol Chem, 2005, 396: 84-92

47 Zhang J, Liu Q, Liu N Q, et al. Nicotine reduces $\beta$-amyloidosis by regulating metal homeostasis. FASEB J, 2006, 20: 1212-1214

48 Liu Q, Zhang J, Qin C, et al. Dissecting the signalling pathway of nicotine-mediated neuroprotection in a mouse Alzheimer disease model. FASEB J, 2007, 21: 61-73

49 Zhao B L. The molecular mechanism of treatment of Alzheimer's disease and Parkinson's disease by nicotine. Acta Biophys China, 2007, 23: 81-92

50 Di X, Yan J, Zha Y, et al. L-theanine protects the APP (Swedish mutation) transgenic SH-SY5Y cell against glutamate-induced excitotoxicity via inhibition of the NMDA receptor pathway. Neuroscience, 2010, 168: 778-786

Open Access This article is distributed under the terms of the Creative Commons Attribution License which permits any use, distribution, and reproduction in any medium, provided the original author(s) and source are credited. 